\title{
Structural origin of the high glass-forming ability in Gd doped bulk metallic glasses
}

\author{
Liang Yang ${ }^{\text {a) }}$ and Gu-Qing Guo \\ College of Materials Science and Technology, Nanjing University of Aeronautics and Astronautics, \\ Nanjing 210016, People's Republic of China
}

(Received 18 June 2010; accepted 12 August 2010; published online 30 August 2010)

\begin{abstract}
The structural origin of the high glass-forming ability (GFA) in Gd-doped CuZrAl bulk metallic glasses was investigated via synchrotron radiation techniques combined with simulations. It is found that 2 at. \% Gd addition increases and stabilizes the solute-centered clusters, which leads to the relatively high atomic- and cluster-level packing efficiency and GFA in $\mathrm{Cu}_{46} \mathrm{Zr}_{45} \mathrm{Al}_{7} \mathrm{Gd}_{2}$ alloy. However, the presence of $\mathrm{Al}-\mathrm{Gd}$ solute-solute bonding in $\mathrm{Cu}_{46} \mathrm{Zr}_{42} \mathrm{Al}_{7} \mathrm{Gd}_{5}$ decreases the packing efficiency, deteriorating the GFA of this alloy. These findings may extend our understanding on the sensitive dependence of GFA on the concentration of doping atoms in a number of multicomponent bulk metallic glasses. (C) 2010 American Institute of Physics. [doi:10.1063/1.3485117]
\end{abstract}

Recently, the minor addition technique has been extensively applied to search for bulk metallic glasses with high glass-forming ability (GFA) and unique properties. ${ }^{1-4}$ For instance, it was found that minor addition in $\mathrm{CuZrAl}$ alloys would enhance its GFA that amorphous rods with centimeterscale critical diameter could be fabricated, ${ }^{5-11}$ which indicates that CuZrAl-based multicomponent bulk metallic glasses have potential application as engineering materials. So far, phase separation and symmetry of clusters have been studied, which were suggested to contribute to the enhanced GFA in Gd-doped CuZrAl alloys. ${ }^{12,13}$ However, the origin of the high GFA caused by microalloying is still not well understood. In particular, the atomic structures of these Gddoped amorphous alloys are not revealed, which may have a significant impact upon their formation. ${ }^{4}$ In this work, a series of state-of-the-art synchrotron radiation-based experiments and simulations are performed to investigate the atomic structures of CuZrAlGd glassy alloys. It is found that minor Gd addition can change the local structure around solute atoms (such as $\mathrm{Al}$ atoms), contributing to a high packing efficiency and the increase in GFA. We also explained the sensitive dependence of GFA on the Gd concentration demonstrated by experiments ${ }^{9-11}$ from the perspective of atomic structure.

$\mathrm{Cu}_{46} \mathrm{Zr}_{47-\mathrm{x}} \mathrm{Al}_{7} \mathrm{Gd}_{\mathrm{x}}(\mathrm{x}=0,2,5)$ amorphous ribbons were fabricated using the same preparation method described in previous work. ${ }^{14}$ Their amorphous structural natures were confirmed by $\mathrm{Cu} K_{\alpha}$ x-ray diffraction and high-resolution transmission electron microscopy. Subsequently, another synchrotron radiation-based $\mathrm{x}$-ray diffraction measurement was performed for all samples at beam line BW5 of Hasylab in Germany, with high energy x-rays of $108.9 \mathrm{keV}$. Twodimensional diffraction patterns were recorded by a Mar345 image plate, and further transferred into reciprocal space data via a standard procedure of reduction, resulting in a structure factor $\mathrm{S}(\mathrm{Q})$ and correspondingly reduced to a pair distribution function $\mathrm{G}(\mathrm{r})$. Transmission mode was adopted to measure $\mathrm{Zr} K$-edge $(17.998 \mathrm{keV}), \mathrm{Cu} K$-edge $(8.979 \mathrm{keV})$ and Gd $L_{3}$-edge $(7.243 \mathrm{keV})$ extended $x$-ray absorption fine structure (EXAFS) for ribbon samples at beam lines X1 and

\footnotetext{
${ }^{\text {a) }}$ Author to whom correspondence should be addressed. Electronic mail: yangliang@nuaa.edu.cn.
}

E4 in Hasylab. The EXAFS data were further normalized to obtain high signal-to-noise ratio spectra via a standard procedure $^{15}$ by using software VIPER. Moreover, reverse Monte Carlo (RMC) simulation upon four sets of S(Q) and EXAFS data simultaneously ${ }^{16,17}$ was carried out by using cubic boxes containing 40000 atoms to match the selected $\mathrm{Cu}_{46} \mathrm{Zr}_{47-\mathrm{x}} \mathrm{Al}_{7} \mathrm{Gd}_{\mathrm{x}}$ compositions. Finally, the structural model obtained by RMC simulation was analyzed by using the Voronoi tessellation method. ${ }^{18,19}$

Figures 1(a)-1(d) show the experimental $\mathrm{S}(\mathrm{Q}), \mathrm{Zr}$, $\mathrm{Cu} K$-edge, and $\mathrm{Gd} L_{3}$-edge EXAFS data of $\mathrm{Cu}_{46} \mathrm{Zr}_{47-\mathrm{x}} \mathrm{Al}_{7} \mathrm{Gd}_{\mathrm{x}}$. Slight differences are detected in Fig. 1. Because of the rather low and experimentally inaccessible energy value of the Al $K$-edge $(1.560 \mathrm{keV})$, EXAFS did not allow to measure the local structure around the $\mathrm{Al}$ atoms. Therefore, more detailed structural information is needed. The RMC-base simulated patterns of $\mathrm{Cu}_{46} \mathrm{Zr}_{45} \mathrm{Al}_{7} \mathrm{Gd}_{2}$ (those of $\mathrm{Cu}_{46} \mathrm{Zr}_{47} \mathrm{Al}_{7}$ and $\mathrm{Cu}_{46} \mathrm{Zr}_{42} \mathrm{Al}_{7} \mathrm{Gd}_{5}$ are not shown here) are plotted in Figs. 2(a) and 2(b), along with their corresponding experimental data. The good matching between experimental
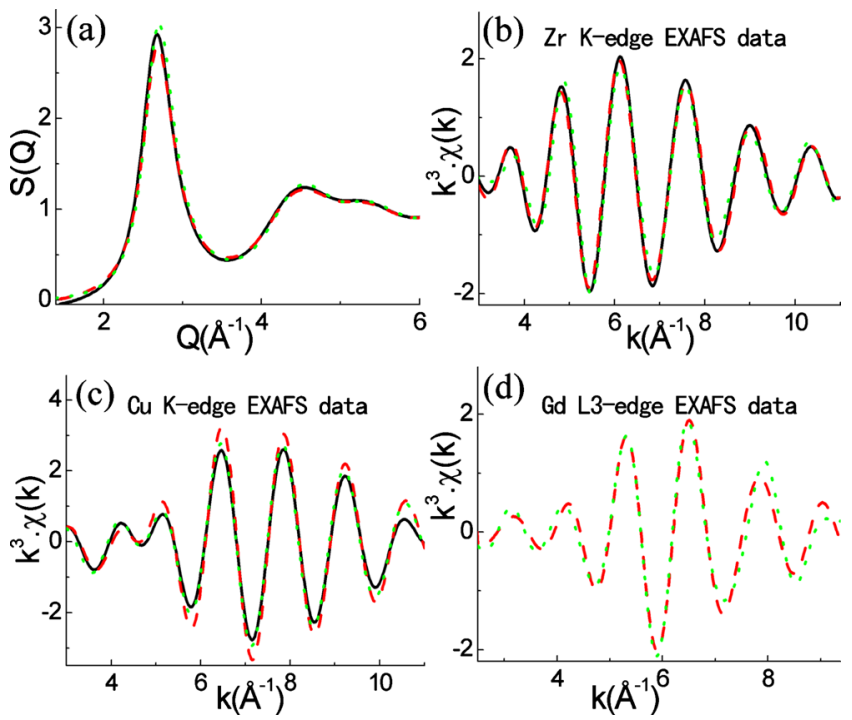

FIG. 1. (Color online) (a) Structure factor $\mathrm{S}(\mathrm{Q})$, (b) $\mathrm{Zr} K$-edge, (c) $\mathrm{Cu} K$-edge, and (d) Gd $L_{3}$-edge EXAFS spectra. The solid, dashed, and dotted lines denote $\mathrm{Cu}_{46} \mathrm{Zr}_{47} \mathrm{Al}_{7}, \mathrm{Cu}_{46} \mathrm{Zr}_{45} \mathrm{Al}_{7} \mathrm{Gd}_{2}$, and $\mathrm{Cu}_{46} \mathrm{Zr}_{42} \mathrm{Al}_{7} \mathrm{Gd}_{5}$, respectively. 

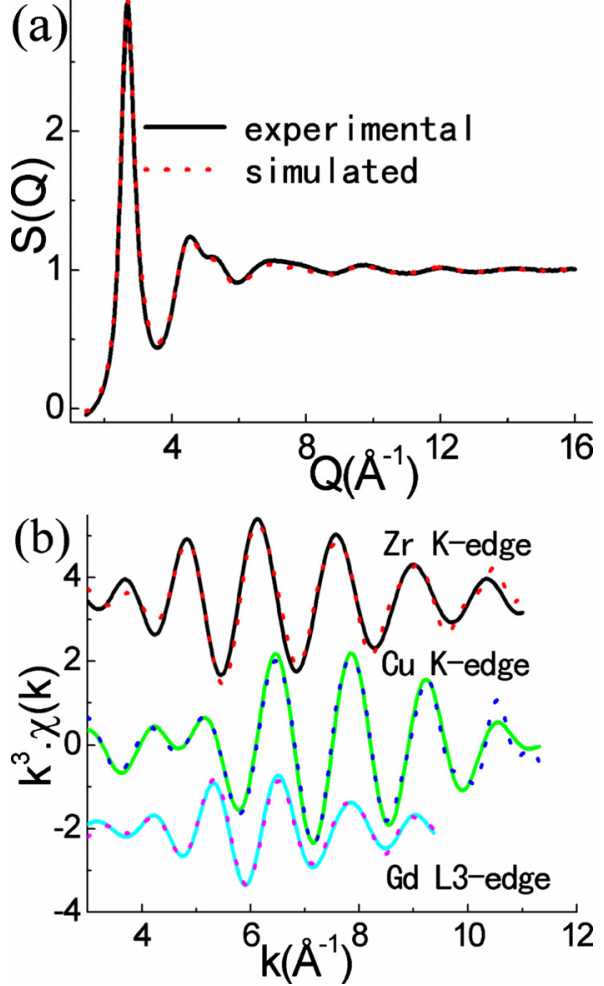

FIG. 2. (Color online) Experimental (solid line) and simulated (dotted line) curves of (a) $\mathrm{S}(\mathrm{Q})$, (b) $\mathrm{Zr} K$-edge, $\mathrm{Cu} K$-edge, and $\mathrm{Gd} L_{3}$-edge EXAFS.

and simulated pairs confirms the quality of this simulation. Furthermore, the atomic-level structural results of $\mathrm{Cu}_{46} \mathrm{Zr}_{47-\mathrm{x}} \mathrm{Al}_{7} \mathrm{Gd}_{\mathrm{x}}$ samples could be deduced from the RMC simulated structural model, which are listed in Table I, including the first-shell coordination numbers $(\mathrm{CNs})$ and atomic pair distances. ${ }^{17}$ The cut-off distances are set to be $3.90 \AA, 3.60 \AA, 3.60 \AA, 4.10 \AA, 3.30 \AA, 3.30 \AA, 3.80 \AA, 3.40$ $\AA$, $3.90 \AA$, and $4.50 \AA$ for $\mathrm{Zr}-\mathrm{Zr}, \mathrm{Zr}-\mathrm{Cu}, \mathrm{Zr}-\mathrm{Al}, \mathrm{Zr}-\mathrm{Gd}$, $\mathrm{Cu}-\mathrm{Cu}, \mathrm{Cu}-\mathrm{Al}, \mathrm{Cu}-\mathrm{Gd}, \mathrm{Al}-\mathrm{Al}, \mathrm{Al}-\mathrm{Gd}$, and $\mathrm{Gd}-\mathrm{Gd}$ atomic pairs, respectively. It is found that both the CNs and pair distances around $\mathrm{Cu}$ and $\mathrm{Zr}$ centers barely change when the $\mathrm{Gd}$ concentration increases from 0 to 2 and 5 . However, it is worth noticing that both the $\mathrm{CN}$ of $\mathrm{Al}$ centers and $\mathrm{Al}-\mathrm{Zr}$

TABLE I. Atomic structure information, including: first-shell CNs of $M(M=\mathrm{Zr}, \mathrm{Cu}$, $\mathrm{Al}$, and $\mathrm{Gd}$ ) atoms and atomic pair distances obtained by RMC simulation.

\begin{tabular}{|c|c|c|c|c|c|c|}
\hline & \multicolumn{2}{|c|}{$\mathrm{Cu}_{46} \mathrm{Zr}_{47} \mathrm{Al}_{7}$} & \multicolumn{2}{|c|}{$\mathrm{Cu}_{46} \mathrm{Zr}_{45} \mathrm{Al}_{7} \mathrm{Gd}_{2}$} & \multicolumn{2}{|c|}{$\mathrm{Cu}_{46} \mathrm{Zr}_{42} \mathrm{Al}_{7} \mathrm{Gd}_{5}$} \\
\hline & $\mathrm{R}(\AA) \pm 0.01$ & $\mathrm{CN} \pm 0.1$ & $\mathrm{R}(\AA) \pm 0.01$ & $\mathrm{CN} \pm 0.1$ & $\mathrm{R}(\AA) \pm 0.01$ & $\mathrm{CN} \pm 0.1$ \\
\hline $\mathrm{Cu}-\mathrm{Cu}$ & 2.59 & 5.0 & 2.60 & 5.1 & 2.60 & 5.2 \\
\hline $\mathrm{Cu}-\mathrm{Zr}$ & 2.88 & 5.4 & 2.89 & 5.0 & 2.89 & 4.5 \\
\hline $\mathrm{Cu}-\mathrm{Al}$ & 2.61 & 0.7 & 2.60 & 0.7 & 2.61 & 0.7 \\
\hline $\mathrm{Cu}-\mathrm{Gd}$ & & & 3.04 & 0.3 & 3.05 & 0.6 \\
\hline $\mathrm{Zr}-\mathrm{Cu}$ & 2.88 & 5.4 & 2.89 & 5.7 & 2.89 & 5.8 \\
\hline $\mathrm{Zr}-\mathrm{Zr}$ & 3.20 & 5.9 & 3.19 & 5.4 & 3.20 & 5.0 \\
\hline $\mathrm{Zr}-\mathrm{Al}$ & 2.82 & 0.8 & 2.76 & 0.8 & 2.80 & 0.7 \\
\hline $\mathrm{Zr}-\mathrm{Gd}$ & & & 3.27 & 0.2 & 3.29 & 0.6 \\
\hline $\mathrm{Al}-\mathrm{Cu}$ & 2.61 & 4.9 & 2.60 & 5.1 & 2.61 & 5.4 \\
\hline $\mathrm{Al}-\mathrm{Zr}$ & 2.82 & 5.7 & 2.76 & 5.1 & 2.81 & 4.9 \\
\hline $\mathrm{Al}-\mathrm{Al}$ & 2.70 & 0.1 & 2.70 & 0.1 & 2.71 & 0.1 \\
\hline $\mathrm{Al}-\mathrm{Gd}$ & & & 3.14 & 0.0 & 3.15 & 0.4 \\
\hline $\mathrm{Gd}-\mathrm{Cu}$ & & & 3.04 & 6.7 & 3.05 & 6.8 \\
\hline $\mathrm{Gd}-\mathrm{Zr}$ & & & 3.42 & 5.8 & 3.43 & 5.2 \\
\hline $\mathrm{Gd}-\mathrm{Al}$ & & & 3.14 & 0.1 & 3.15 & 0.5 \\
\hline $\mathrm{Gd}-\mathrm{Gd}$ & & & & 0.0 & 3.56 & 0.2 \\
\hline
\end{tabular}
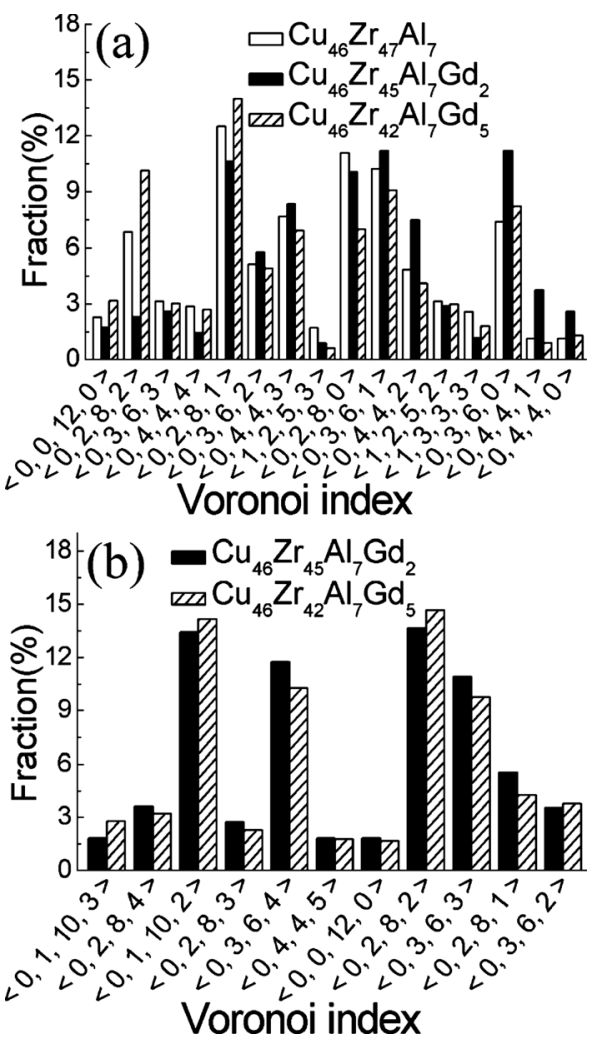

FIG. 3. Distribution of Voronoi clusters centered with (a) Al and (b) Gd atoms.

length in $\mathrm{Cu}_{46} \mathrm{Zr}_{45} \mathrm{Al}_{7} \mathrm{Gd}_{2}$ are obviously smaller than those in $\mathrm{Cu}_{46} \mathrm{Zr}_{47} \mathrm{Al}_{7}$ and $\mathrm{Cu}_{46} \mathrm{Zr}_{42} \mathrm{Al}_{7} \mathrm{Gd}_{5}$. This indicates that the Alcentered local structure in $\mathrm{Cu}_{46} \mathrm{Zr}_{45} \mathrm{Al}_{7} \mathrm{Gd}_{2}$ may be different from those in $\mathrm{Cu}_{46} \mathrm{Zr}_{47} \mathrm{Al}_{7}$ or $\mathrm{Cu}_{46} \mathrm{Zr}_{42} \mathrm{Al}_{7} \mathrm{Gd}_{5}$.

To obtain more structural information, the Voronoi tessellation method was performed to investigate the microstructure at cluster scale. ${ }^{20}$ Considering the concentrations of $\mathrm{Zr}, \mathrm{Cu}, \mathrm{Al}$, and $\mathrm{Gd}$ components in the selected $\mathrm{ZrCuAlGd}$ alloys, $\mathrm{Zr}$ and $\mathrm{Cu}$ atoms should be regarded as solvents while $\mathrm{Al}$ and $\mathrm{Gd}$ atoms as solute spheres. Usually solutes are regarded as the centers while solvents are regarded as the shell atoms of a cluster in some atomic structural models, such as the quasiequivalent cluster model ${ }^{21}$ and the efficient dense packing models. ${ }^{22,23}$ Thus, we only deduce Voronoi clusters centered with the solute spheres ( $\mathrm{Al}$ and $\mathrm{Gd}$ atoms) here. The corresponding distributions of various Voronoi clusters with $\mathrm{Al}$ or Gd centers are plotted in Fig. 3. It is interesting that the clusters with large (small) CNs have obviously lower (higher) fractions in $\mathrm{Cu}_{46} \mathrm{Zr}_{45} \mathrm{Al}_{7} \mathrm{Gd}_{2}$ than in $\mathrm{Cu}_{46} \mathrm{Zr}_{47} \mathrm{Al}_{7}$. For instance, the 12-CN "large" clusters indexed as $\langle 0,0,12,0\rangle,\langle 0,2,8,2\rangle$, and $\langle 0,3,6,3\rangle$ have a total weight of $12 \%$ and $7 \%$ in $\mathrm{Cu}_{46} \mathrm{Zr}_{47} \mathrm{Al}_{7}$ and $\mathrm{Cu}_{46} \mathrm{Zr}_{45} \mathrm{Al}_{7} \mathrm{Gd}_{2}$, respectively. However, when adding 5 at. \% Gd in $\mathrm{CuZrAl}$, on the contrary, the large (small) clusters account for relatively higher (lower) fractions. Concerning the clusters centered with $\mathrm{Gd}$ atoms, it is observed that their distributions are almost the same in both Gd-containing glassy alloys. To further analyze the cluster-scale local structure, we calculated the volumes of Voronoi clusters centered with $\mathrm{Al}$ or $\mathrm{Gd}$ solute atoms in $\mathrm{Cu}_{46} \mathrm{Zr}_{47-\mathrm{x}} \mathrm{Al}_{7} \mathrm{Gd}_{\mathrm{x}}$ samples. The volume difference of $\mathrm{Al}$ - or $\mathrm{Gd}$-centered clusters between $\mathrm{Cu}_{46} \mathrm{Zr}_{47} \mathrm{Al}_{7}$ and $\mathrm{Cu}_{46} \mathrm{Zr}_{45} \mathrm{Al}_{7} \mathrm{Gd}_{2}$, and between $\mathrm{Cu}_{46} \mathrm{Zr}_{45} \mathrm{Al}_{7} \mathrm{Gd}_{2}$ and $\mathrm{Cu}_{46} \mathrm{Zr}_{42} \mathrm{Al}_{7} \mathrm{Gd}_{5}$ are plotted in Fig. 4. It is found that all the 

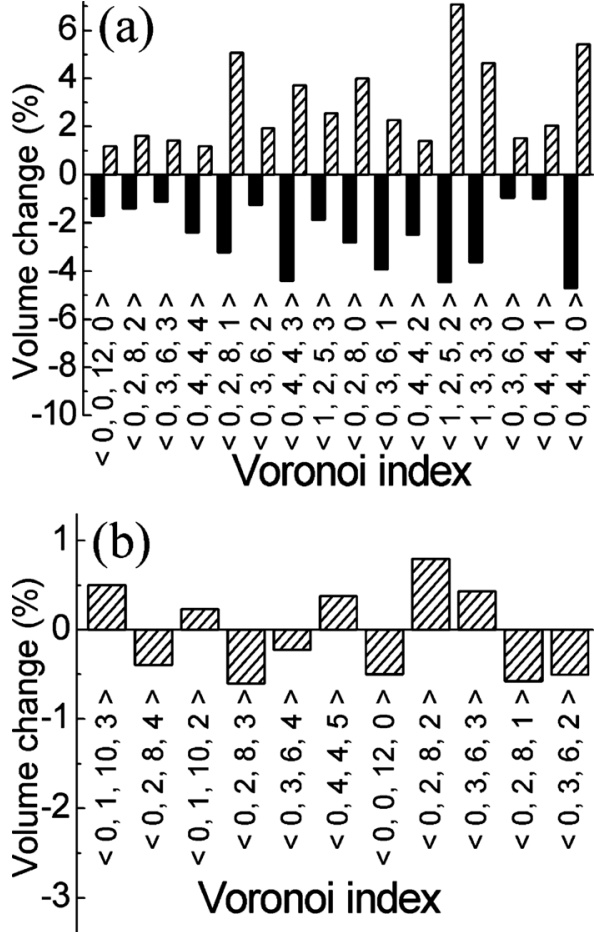

FIG. 4. The volume differences of Voronoi clusters centered with (a) $\mathrm{Al}$ and (b) $\mathrm{Gd}$ atoms. The solid and striped columns denote the relative volume differences between $\mathrm{Cu}_{46} \mathrm{Zr}_{45} \mathrm{Al}_{7} \mathrm{Gd}_{2}$ and $\mathrm{Cu}_{46} \mathrm{Zr}_{47} \mathrm{Al}_{7}$

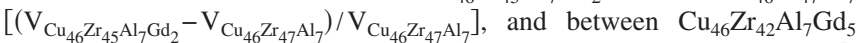

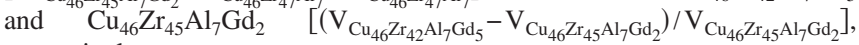
respectively.

Al-centered clusters in $\mathrm{Cu}_{46} \mathrm{Zr}_{45} \mathrm{Al}_{7} \mathrm{Gd}_{2}$ are smaller than their counterparts in $\mathrm{Cu}_{46} \mathrm{Zr}_{47} \mathrm{Al}_{7}$, which is due to the fact that $\mathrm{Al}-\mathrm{Zr}$ bonds are relatively shorter in the former. However, the volumes of all the Al-centered clusters increase instead of decrease when Gd concentration increases from $2 \%$ to $5 \%$. For various Gd-centered clusters, there is no obvious volumetric increase or decrease between these two samples. These results also indicate that the local structure around $\mathrm{Al}$ atoms rather than $\mathrm{Gd}$ centers is strongly related to the $\mathrm{Gd}$ concentration.

Based on the results deduced above, we can reveal the origin of enhanced GFA caused by 2 at. \% Gd addition in $\mathrm{CuZrAl}$ from structural perspective as follows. First, as suggested in an efficient packing model, if the atomic structure is made up by dense packing of smaller (larger) clusters centered with $\alpha(\beta)$ solute atoms, it contributes to the formation of glassy alloys. ${ }^{24}$ In $\mathrm{Cu}_{46} \mathrm{Zr}_{45} \mathrm{Al}_{7} \mathrm{Gd}_{2}$, it is evident that $\mathrm{Al}$ (Gd) solute atoms are apt to locate in the center of relatively smaller (larger) clusters, leading to avoidance of solutesolute bonding. ${ }^{25}$ These solute-centered clusters should be the favored building blocks in glassy alloys. Compared with $\mathrm{Cu}_{46} \mathrm{Zr}_{47} \mathrm{Al}_{7}$, more $\mathrm{Cu}$ and $\mathrm{Zr}$ solvents atoms take the shell sites in the $\mathrm{Al}$ or $\mathrm{Gd}$ centered clusters, which result in higher packing efficiency in atomic structure. ${ }^{26}$ Second, it is confirmed that the volumes of various $\mathrm{Al}$-centered clusters in $\mathrm{Cu}_{46} \mathrm{Zr}_{45} \mathrm{Al}_{7} \mathrm{Gd}_{2}$ universally decrease compared with their counterparts in $\mathrm{Cu}_{46} \mathrm{Zr}_{47} \mathrm{Al}_{7}$, which indicates that atoms are more densely packed inside the clusters in the former. Both the atomic and cluster dense packing effects discussed above can significantly enhance the GFA of $\mathrm{Cu}_{46} \mathrm{Zr}_{45} \mathrm{Al}_{7} \mathrm{Gd}_{2}$ alloy.

On the other hand, the deterioration of GFA by adding 5 at. \% $\mathrm{Gd}$ in $\mathrm{CuZrAl}$ also could be explained. First, it is shown in Table I that some $\mathrm{Al}$ and $\mathrm{Gd}$ solute atoms are directly connected with each other in $\mathrm{Cu}_{46} \mathrm{Zr}_{42} \mathrm{Al}_{7} \mathrm{Gd}_{5}$ while not in $\mathrm{Cu}_{46} \mathrm{Zr}_{45} \mathrm{Al}_{7} \mathrm{Gd}_{2}$, which leads to structural frustration in forming ideal solute-centered clusters ${ }^{21,24,25}$ densely packed in the former. Second, some Gd large atoms take the shell sites in $\mathrm{Al}$-centered clusters in $\mathrm{Cu}_{46} \mathrm{Zr}_{42} \mathrm{Al}_{7} \mathrm{Gd}_{5}$. These clusters accordingly expand by $1 \%-6 \%$ compared with those in $\mathrm{Cu}_{46} \mathrm{Zr}_{45} \mathrm{Al}_{7} \mathrm{Gd}_{2}$, which may decrease the atomic-level packing efficiency inside these clusters.

In summary, the atomic structures of $\mathrm{Cu}_{46} \mathrm{Zr}_{47-\mathrm{x}} \mathrm{Al}_{7} \mathrm{Gd}_{\mathrm{x}}$ glassy alloys are investigated. It is revealed that 2 at. $\% \mathrm{Gd}$ addition can affect the local structure around $\mathrm{Al}$ atoms, leading to higher atomic- and cluster-level packing efficiency. This is the structural origin of high GFA in $\mathrm{Cu}_{46} \mathrm{Zr}_{45} \mathrm{Al}_{7} \mathrm{Gd}_{2}$. However, when 5 at. \% Gd atoms are added, its packing efficiency decreases rather than increases due to the direct $\mathrm{Al}-\mathrm{Gd}$ solute-solute bonding, resulting in the deteriorated GFA in this composition.

The authors would like to thank HASYLAB in Germany, BSRF in Beijing, and NSRL in Hefei for the use of the advanced synchrotron radiation facilities. Financial support from the National Natural Science Foundation of China (Grant No. 10805027), the Natural Science Foundation of Jiangsu Province (Grant No. BK2008397), and the NUAA Research Funding (Grant No. NS2010168) are gratefully acknowledged.

\footnotetext{
${ }^{1}$ A. Inoue, Acta Mater. 48, 279 (2000).

${ }^{2}$ W. H. Wang, C. Dong, and C. H. Shek, Mater. Sci. Eng. R. 44, 45 (2004). ${ }^{3}$ Z. P. Lu, C. T. Liu, J. R. Thompson, and W. D. Porte, Phys. Rev. Lett. 92, 245503 (2004).

${ }^{4}$ W. H. Wang, Prog. Mater. Sci. 52, 540 (2007).

${ }^{5}$ Q. S. Zhang, W. Zhang, and A. Inoue, Scr. Mater. 55, 711 (2006).

${ }^{6}$ C. L. Dai, H. Guo, Y. Shen, Y. Li, E. Ma, and J. Xu, Scr. Mater. 54, 1403 (2006).

${ }^{7}$ D. H. Xu, G. Duan, and W. L. Johnson, Phys. Rev. Lett. 92, 245504 (2004).

${ }^{8}$ Y. Shen, E. Ma, and J. Xu, J. Mater. Sci. Technol. 24, 149 (2008).

${ }^{9}$ P. Yu, H. Y. Bai, and W. H. Wang, J. Mater. Res. 21, 1674 (2006).

${ }^{10}$ H. M. Fu, H. Wang, H. F. Zhang, and Z. Q. Hu, Scr. Mater. 55, 147 (2006).

${ }^{11}$ X. Xu, L. Y. Chen, G. Q. Zhang, L. N. Wang, and J. Z. Jiang, Intermetallics 15, 1066 (2007).

${ }^{12}$ E. S. Park, J. S. Kyeong, and D. H. Kim, Scr. Mater. 57, 49 (2007).

${ }^{13}$ X. K. Xi, M. T. Sandor, Y. H. Liu, W. H. Wang, and Y. Wu, Scr. Mater. 61, 967 (2009).

${ }^{14}$ X. D. Wang, Q. K. Jiang, Q. P. Cao, J. Bednarcik, H. Franz, and J. Z. Jiang, J. Appl. Phys. 104, 093519 (2008).

${ }^{15}$ L. Yang, J. Z. Jiang, T. Liu, T. D. Hu, and T. Uruga, Appl. Phys. Lett. 87, 061918 (2005).

${ }^{16}$ W. K. Luo, H. W. Sheng, F. M. Alamgir, J. M. Bai, J. H. He, and E. Ma Phys. Rev. Lett. 92, 145502 (2004).

${ }^{17}$ L. Yang, S. Yin, X. D. Wang, Q. P. Cao, J. Z. Jiang, K. Saksl, and H. Franz, J. Appl. Phys. 102, 083512 (2007).

${ }^{18}$ J. L. Finney, Nature (London) 266, 309 (1977).

${ }^{19}$ V. S. Stepanyuk, A. Szasz, A. A. Katsnelson, O. S. Trushin, H. Müller, and H. Kirchmayr, J. Non-Cryst. Solids 159, 80 (1993).

${ }^{20}$ T. Kondo and K. Tsumuraya, J. Chem. Phys. 94, 8220 (1991).

${ }^{21}$ H. W. Sheng, W. K. Luo, F. M. Alamgir, J. M. Bai, and E. Ma, Nature (London) 439, 419 (2006).

${ }^{22}$ D. B. Miracle, Acta Mater. 54, 4317 (2006).

${ }^{23}$ D. Ma, A. D. Stoica, L. Yang, X. L. Wang, Z. P. Lu, J. Neuefeind, M. J. Kramer, J. W. Richardson, and T. Proffen, Appl. Phys. Lett. 90, 211908 (2007)

${ }^{24}$ D. B. Miracle, Nature Mater. 3, 697 (2004).

${ }^{25}$ D. Ma, A. D. Stoica, and X. L. Wang, Appl. Phys. Lett. 91, 021905 (2007)

${ }^{26}$ D. Ma, A. D. Stoica, X. L. Wang, Z. P. Lu, M. Xu, and M. Kramer, Phys. Rev. B 80, 014202 (2009).
} 